\title{
Effect Of Colchicine On The Histology Of Spleen And Testis Of Albino Rats
}

\author{
Nabila A. R. Abdel Motaal \\ Radiation Biology Department, National Centre for Radiation Research \\ and Technology, Cairo, Egypt.
}

\begin{abstract}
The aim of this work is to study the effect of colchicine administration on the histology of spleen and testis of albino rat.

Colchicine was given in a daily dose of $3 \mathrm{mg} / \mathrm{kg}$ body weight for five days. Animals were sacrificed at 1, 4 and 7 days following treatment. Histopathological studies of the spleen and testis were undertaken.

Histological examination of spleen showed that colchicine caused histopathological changes in spleen manifested by massive haemorrhage, highly expanded red pulps accompanied by reduced white pulps with multi small degenerated areas, disturbed architecture, degenerated areas wer occupied by the hemorrhagic areas, prominent haemosiderin deposition, increased number of megakaryocytes in red pulp and subcapsular edema. These histopathological changes depend on the duration of colchicine intake.

Histological examination of the testis one, four and seven days post treatment with colchicine showed dilatation and congestion of interstitial blood vessels, moderate degeneration of spermatogoneal cells, debris of spermatozoa could be detected in the lumen of the seminiferous tubules. The testis also suffered from interstitial edema with signs of fatty degeneration and degeneration of spermatogoneal cells lining some seminferous tubules. Complete destruction with hypocellularity in the spermatogenic layers in some seminiferous tubules and others contained only the debris of germ cells and disturbed nuclei of spermatogoneal cells with appearance of giant cells with highly reduced number of Leydig cells which contained pyknotic nuclei were also noticed in some examined sections.

These results indicate that colchicine is considered as a toxic drug to the spleen and testis at double therapeutic doses as indicated by the histological changes.
\end{abstract}

\section{Introduction}

Colchicine is a naturally occurring alkaloid with weak anti-inflammatory activity derived from the autumn crocus Colchicum automnale and the glory lily Gloriosa superba. It has been used extensively in the treatment of gout for many centuries and also been recommended in preventing attacks of familial Mediterranean fever (Zemer et al., 1974) and in the treatment of primary biliary cirrhosis (Kaplan et al., 1986), amyloidosis (Cohen et al., 1987), and condyloma acuminate (Naidus et al., 1977).

Colchicine is an anti-mitotic agent and has an effective role for acute gouty arthritis. Colchicine interferes with the formation of microtubules by binding to microtubular protein (tubulin) and causing depolymerization of microtubules (Joshi, 1998). Microtubules are involved in diverse functions, including cell movement, vesicle transport, and chromosome segregation during mitosis. It has been shown that colchicine can be either cytotoxic or protective against cytotoxicity. Colchicine has been reported to protect against a variety of hepatotoxic insults. It was reported to improve survival in a clinical trial for alcoholic cirrhosis (Kershenobich et al., 1988).

Colchicine is rapidly absorbed from the gastrointestinal tract after ingestion. It undergoes significant first pass hepatic metabolism, which primarily involves deacetylation. Subsequent to this, the metabolites undergo widespread 
enterohepatic recirculation before being excreted in bile and faeces. It is thought that the extended time period during which the gastrointestinal mucosal cells are exposed to colchicine may explain the prominence of the gastrointestinal symptoms of toxicity. Renal clearance also accounts for $10 \%-20 \%$ of colchicine removal and if normal renal function exists larger fractions can be excreted via this route if a toxic amount has been ingested. Increased urinary excretion also occurs in the presence of hepatic disease, as there is a reduction in the capacity for deacetylation. However, if renal and hepatic diseases coexist the possibility of toxicity greatly increases (Borron et al., 1996).

Colchicine results in dose dependant accumulation of cells with large hyperchromatic nuclei in the mantle zone of the Blymphocyte follicle of spleen (El-Shafeey et al., 2000).

Overdose with colchicine is uncommon. It exhibits a low therapeutic index although there is a great variation in the dose required for significant morbidity. Patients have survived ingestion of more than $60 \mathrm{mg}$ (Baud et al., 1995) but conversely others have died after ingesting only 7 $\mathrm{mg}$ over a prolonged period (MacLeod and Phillips, 1947). There does not seem to be any clear cut separation between non-toxic, toxic or lethal doses of colchicine. Indeed, symptoms of gastrointe-stinal toxicity such as nausea, vomiting, diarrhoea and abdominal pain are seen in $80 \%$ of patients on full therapeutic doses and are used as the clinical endpoint in dose titration (Milne and Meek, 1998).

Overdose with colchicine constitutes a toxicological emergency and rapid intervention is required. There are various suggestions to explain the effect that colchicine has on the heart. It is thought that there may be a direct toxic effect on the myocardial cells with impairment of impulse generation and cardiac conduction (Markland, 1971 and Stahl et al., 1979). This has not been proved, although a similar mechanism of direct toxicity is seen on the cells of skeletal muscle (Stemmermann and Hayashi, 1971). It is also possible that the profound acidbase disturbances and electrolyte derange- ments associated with overdose will play a significant part (Borron et al., 1996).

Due to the vital importance of colchicine this work was undertaken to investigate whether colchicine administration to normal rats has any histological effects on the spleen or on the testis tissues or on both of them.

\section{Material and methods}

\section{Animals}

Male Swiss albino rats (120-140) were used. The animals were housed in specially designed cages and were kept in controlled room in the animal house facility of National Centre for Radiation Research and Technology (NCRRT) at a maintained good temperature and humidity. They were given standard food and normal tap water daily.

\section{Colchicine treatment}

Colchicine (Sigma) was given as intra peritoneal injections with a dose of $3 \mathrm{mg} / \mathrm{kg} /$ day for 5 days (double the therapeutic dose).

\section{Experimental design}

The animals were divided into four groups of 4 each according to the time of sampling: (Group 1): control group, the animals received i.p. injection of saline. (Group 2): The animals were sacrificed at one day post treatment with colchicine. (Group 3): The animals were sacrificed at four days post treatment with colchicine. (Group 4): The animals were sacrificed at seven days post treatment with colchicine. Histological analysis

Rats of each group were sacrificed at 1,4 and 7 days after treatment with colchicine. Animals were sacrificed by decapitation, the spleen and testis, were excised and fixed in $10 \%$ formalin, dehydrated in ascending grades of ethyl alcohol, cleared in xylol, embedded in molten paraplast at $560 \mathrm{C}$ and cut at 5micron on rotator microtome. The paraffin sections were 
stained with haematoxylin and eosin (Drury and Wallington, 1980). Histopathological studies were undertaken through light microscopy and photomicrographs were made.

\section{Results}

\section{Spleen examination}

Microscopical examination of control, untreated spleen revealed no histopathological changes (Fig. 1).

In examined spleen of rat treated with colchicine after one day post treatment showed small hemorrhagic areas (Fig. 2) and large hemorrhagic area occupied the degenerated area with highly reduced white pulp (Fig. 3).

Massive splenic haemorrhages associated with prominent haemosiderin deposition and highly expanded red pulps accompanied by reduced white pulps with multi small degenerated areas (Fig. 4) as well as presence of megakaryocytes in the red pulp (Fig. 5) were seen in examined liver at four days post treatment.

Moreover, at seven days post treatment the spleen showed subcapsular edema (Fig. 6) as well as massive splenic haemorrhage and haemosiderosis (Fig. 7).

\section{Testis examination}

Examined testis of normal, control rat showed the normal semineferous tubules (Fig. 8). Testis of rat treated with colchicine one day post treatment showed dilatation and congestion of interstitial blood vessels (Figs. 9).

Testis of rat treated with colchicine four days post treatment showed moderate degeneration of spermatogoneal cells. Debris of spermatozoa could be detected in the lumen of the seminiferous tubules (Fig.10).

At seven days the testis suffered from interstitial edema with signs of fatty degeneration and degeneration of spermatogoneal cells lining some semineferous tubules (Fig. 11). Also complete destruction with hypocellularity in the spermatogenic layers in some seminiferous tubules, others contained only the debris of germ cells with disturbed nuclei of spermatogoneal cells with appearance of giant cells with highly reduced number of Leydig cells which contained pyknotic nuclei (Figs. 12 \& 13) were also noticed in some examined sections. 


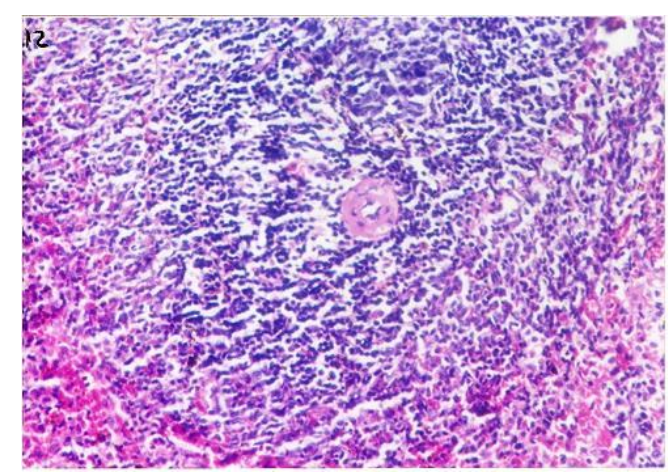

Fig. 1: Spleen of control, untreated rat showing normal white pulp, central arteriole, and red pulp. (Hx \& E stain X 200).

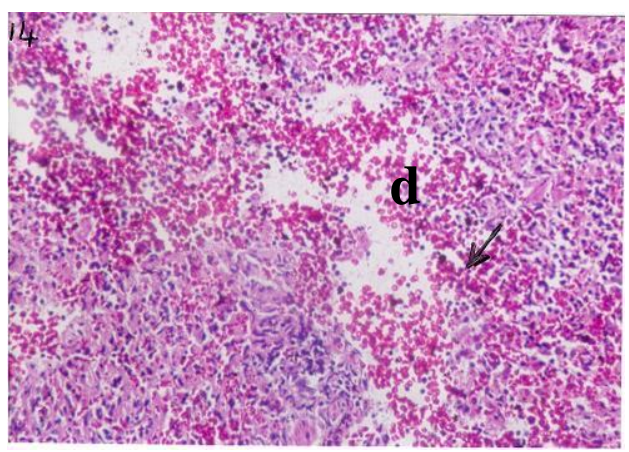

Fig. 3: Spleen of rat treated with colchicine one day post treatment showing large haemorrhagic area $(\uparrow)$ occupied the degenerated area (d) with highly reduced white pulp. (Hx \& E stain X 200).

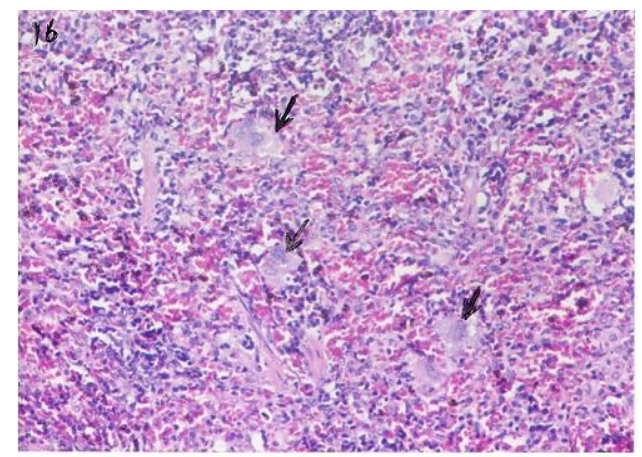

Fig. 5: Spleen of rat treated with colchicine four days post treatment showing lots of megakaryocytes in red pulp (arrows). (Hx \& E stain X 200).

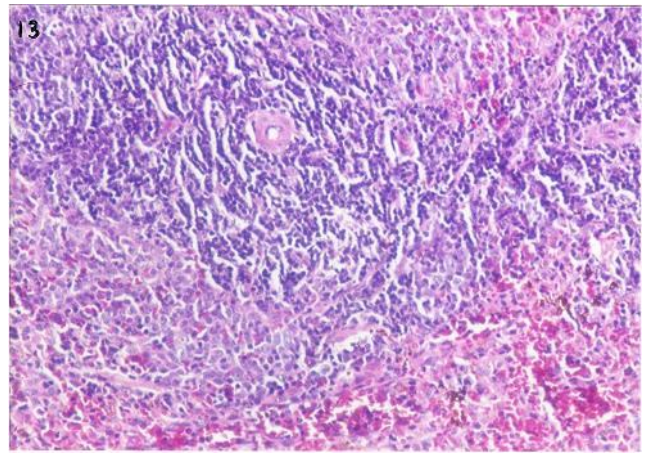

Fig. 2: Spleen of rat treated with colchicine one day post treatment showing small hemorrhagic areas. (Hx \& E stain X 200).

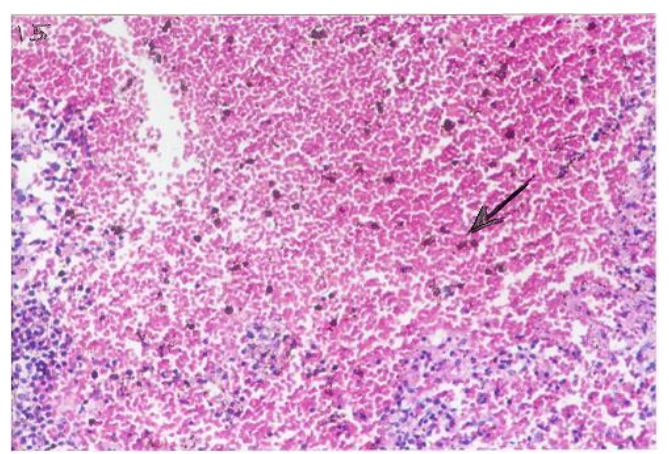

Fig. 4: Spleen of rat treated with colchicine four days post treatment showing massive haemorrhage with prominent haemosiderin deposition $(\uparrow)$ and highly expanded red pulps and reduced white pulps. (Hx \& E stain X 200).

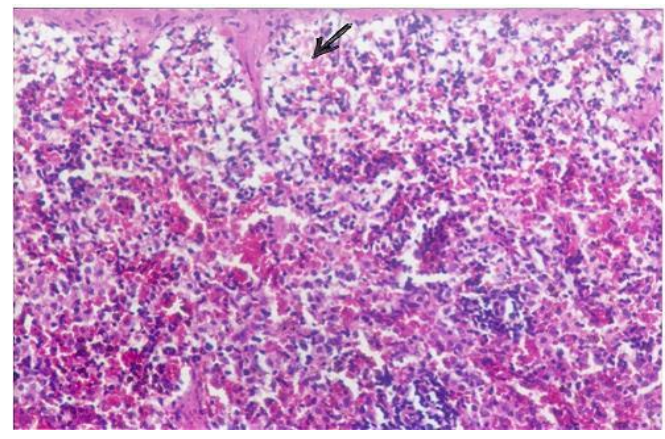

Fig. 6: Spleen of rat treated with colchicine seven days post treatment showing subcapsular edema $(\uparrow) \&$ highly atrophied white pulps with disturbed architecture. (Hx \& E stain X 200). 


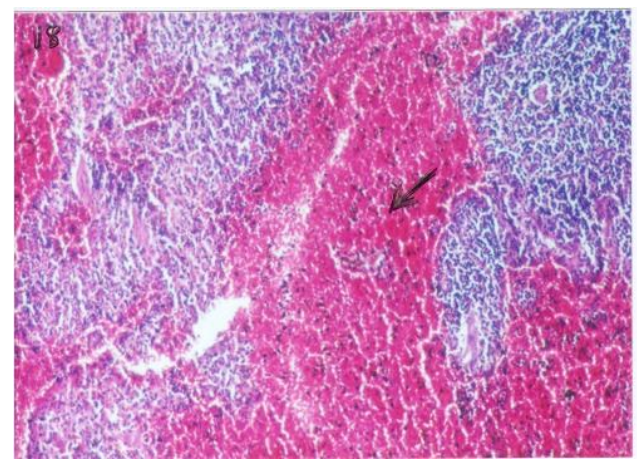

Fig. 7: Spleen of rat treated with colchicine seven days post treatment showing massive haemorrhage and haemosiderosis $(\uparrow)$. (Hx \& E stain X 100).

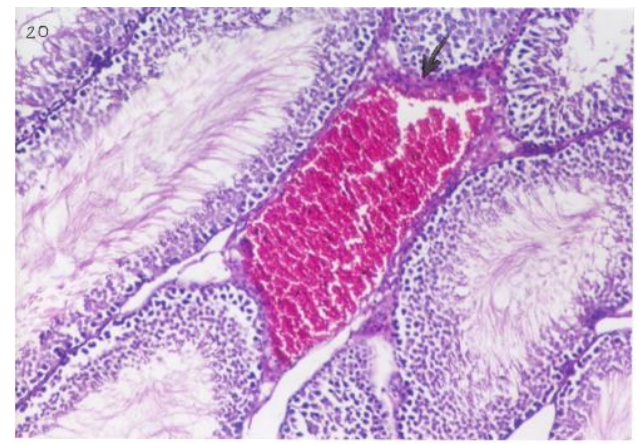

Fig. 9: Testis of rat treated with colchicine one day post treatment showing dilatation and congestion of interstitial blood vessel (arrow). (Hx \& E stain X 100).

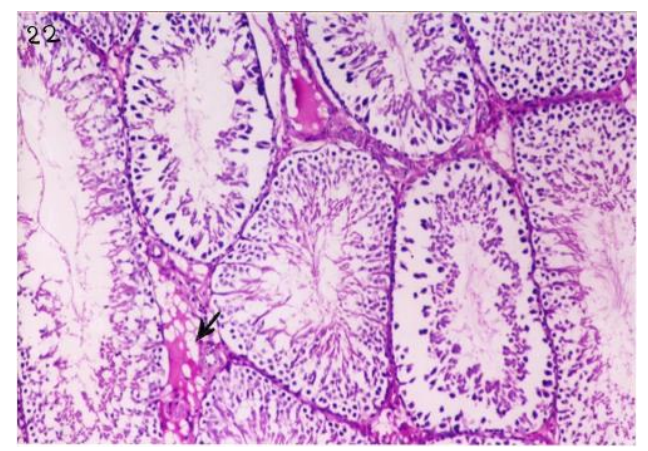

Fig. 11: Testis of rat treated with colchicine seven days post treatment showing interstitial edema (arrow) and degeneration of

spermatogoneal cells lining some seminiferous tubules. (Hx \& E stain X 100).

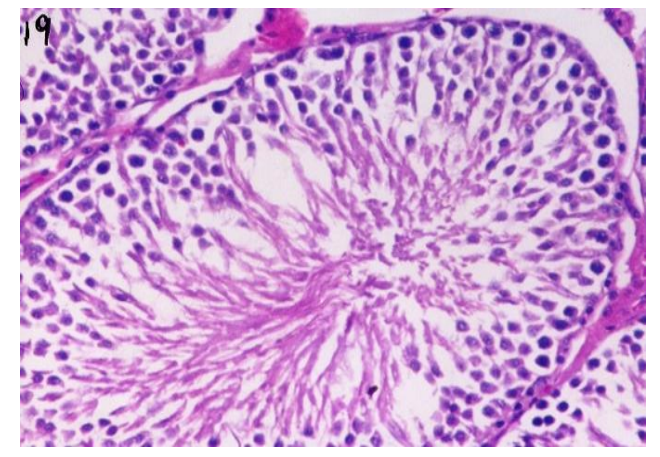

Fig. 8: Testis of control, untreated rat showing the normal histology of semineferous tubules. (Hx \& E stain X 400).

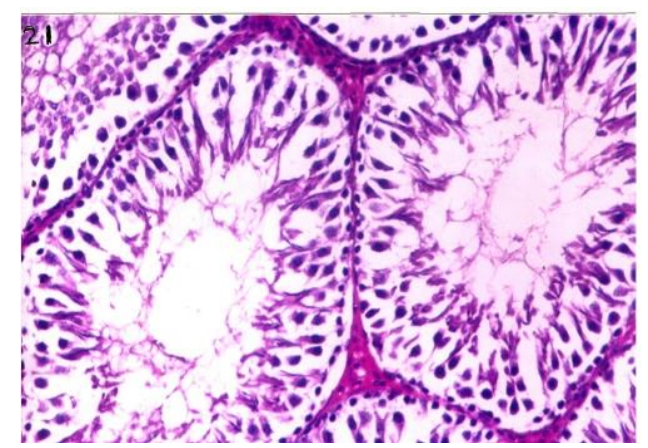

Fig. 10: Testis of rat treated with colchicine four days post treatment showing moderate degeneration of spermatogoneal cells. Debris of spermatozoa in the lumen of the seminiferous tubues is detected. (Hx \& E stain X 200).

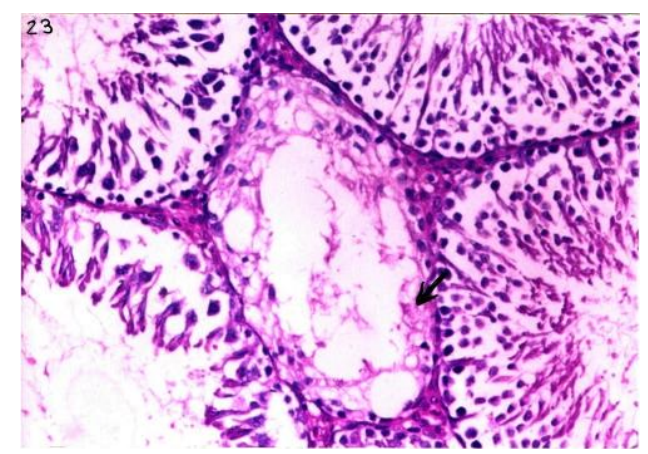

Fig. 12: Testis of rat treated with colchicine seven days post treatment showing complete destruction of spermatogoneal cells lining some seminiferous tubules (arrow). (Hx \& E stain X 200). 


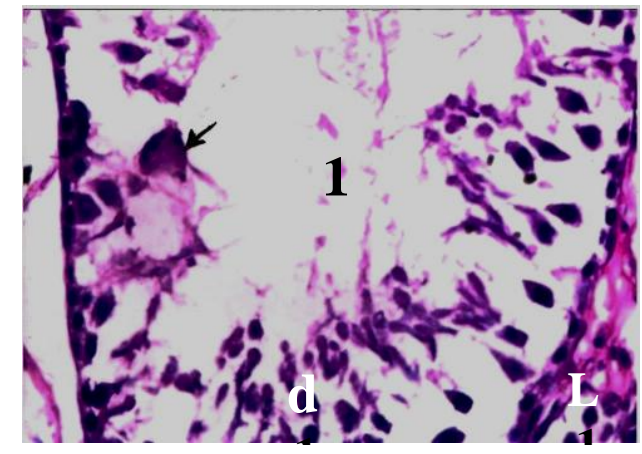

\section{Discussion}

One of the oldest drugs used in the treatment of gout is colchicine and it is still widely used in the treatment of several diseases (Bertram, 1992). Colchicine is rapidly absorbed after oral administration, probably from the jejunum and ileum. It accumulates in kidney, liver, spleen, the gastrointestinal wall and leucocytes. Accumualation in these tissues may lead to toxicity (US Drug Information for the Health Care Professional: Colchicine, 1998). Colchicine has potent anti-mitotic activity, which is caused by its binding, both reversibly and selectively, to tubulin, the microtubular protein that disrupts the function of the mitotic spindles in those cells capable of dividing and migrating (Hood, 1994).

Colchicine is a safe drug when used according to established therapeutic guidelines but causes serious systemic effects if ingested in doses that exceeded the recommendations (Maxwell et al., 2001). As far as side effects go, co lchicine can cause a temporary reduction in the number of leukocytes (white blood cells) in the blood stream; afterward, the leukocyte count can rebound to abnormally high levels. It also causes teratogenic birth defects in lab animals, and so pregnant women with gout should not use colchicine-containing drugs.

In the present study, histological parameters were followed in the spleen and
Fig. 13: Testis of rat treated with colchicine seven days post treatment showing giant cell $(\uparrow)$, increased signs of degeneration with hypertrophied nuclei (d), the lumen of seminiferous tubule is free from sperms (1), with disturbed Leydig cells (L). (Hx \& E stain X 400). testis of rats treated with double therapeutic doses of colchicine.

The results obtained revealed histopathological changes in the spleen and testis. The lesions in the spleen were mainly haemorrhages, haemosiderosis, appearance of megakaryocytes in red pulp, highly reduced white pulp, and subcapsular edema. Previous studies on the effect of colchicine on spleen histology were performed by other authors. El-Shafeey et al. (2000) reported that colchicine drenching at therapeutic and double therapeutic doses inhibits the proliferation of $\mathrm{B}$-and $\mathrm{T}$ lymphocytes and it also induces apoptosis in T-lymphocytes of spleen. This results in the accumulation of hyper chromatic polypoid lymphoblasts and increased phagocytic activity in the spleen. They also reported that the collagen content of the stroma was also reduced under colchicine administration and red blood cells of spleen red pulp were also adversely affected.

Wagenaar (2004) reported that the histopathological examination of the spleen showed that the red pulp of the spleen was severely congested and moderate to severe loss of periarteriolar lymphoid sheaths and splenic corpuscles were evident in the spleen due to accidental colchicine poisoning in a dog.

Bumbasirevie et al. (1996) reported that colchicine resulted in apoptosis in cultured lymphocytes and that the 
quantitative results suggest that hyperchromasia may be due to polyploidy as the amount of DNA per nucleus is high in colchicine treated specimens.

On the other hand, the testis showed interstitial edema with highly reduced number of Leydig cells, degeneration of spermatogoneal cells lining semineferous tubules, appearance of spermatid giant cells and after seven days complete destruction of spermatogoneal cells was seen. Debris of spermatozoa could be detected in the lumen of the seminiferous tubules was seen. In support with our finding Allard et al. (1993) investigated the effect of colchicine, a microtubule-disrupting agent, on the seminiferous epithelium. They observed that colchicine disrupts the cytoskeleton of rat testis seminiferous epithelium in a stagedependent manner.

These changes in the histology of the testis, highly dividing cells, may be due to the fact that colchicines has been considered to be a potent mitotic inhibitor causing an arrest of cell division in metaphase, possibly by interference with formation of the spindle fibers (Eigsti and Dustin, 1955). Although colchicine is taken up equally by all cells it is thought that those which have the highest cell turnover (that is, the greatest mitotic activity) are most affected (Milne and Meek, 1998).

Previous studies were made by Maxwell et al. (2001) and Wagenaar (2004) on accidental and over dose treatment with colchicine. A case was reported by Klintschar et al. (1999) in which two persons confused this highly poisonous plant with wild garlic (Allium ursinum), a popular spice in the Central European cuisine. While one person merely complained about a 3-day episode of nausea, vomiting and watery diarrhea, the second person died of multi-organ system derangements $48 \mathrm{~h}$ after the ingestion of the colchicum leaves. At autopsy hemorrhagic lung oedema, hypocellular bonemarrow, centrilobular fatty necrosis of the liver and necrosis of the proximal convoluted tubule of the kidneys were observed.

In conclusion, this study shows that colchicine, double the therapeutic dose, administration to normal rats, leads to alterations and changes in the histology of spleen and testis. Thus strict regulations must be taken in treating patients with this drug.

\section{References}

1. Allard, E.K.; Johnson, K.J. and Boekelheid, K. (1993): Colchicine disrupts the cytoskeleton of rat testis seminiferous epithelium in a stage-dependent manner. Biol. Reprod., 48(1):143-153.

2. Baud, F.J.; Sabouraud, A. and Vicaut, E. (1995): Brief report: Treatment of severe colchicine overdose with colchicinespecific Fab fragments. N. Engl. J. Med., 332:642-645.

3. Bertram, G.K. (1992): Basic clinical pharmacology. McGraw Hill, London.

4. Borron, S.W.; Scherrmann, J.M. and Baud, F.J. (1996): Markedly altered colchicine kinetics in a fatal intoxication: Examination of contributing factors. Hum. Exp. Toxicol., 15:885-890.

5. Bumbasirevie, V.; Scaro-Milic, A.; Mireie, A. and Djurieie, B. (1996): Apoptosis induced by microtubule disrupting drugs in normal murine thymocytes in vitro. Scanning Microscope, 9: 509-516.

6. Cohen, A.S.; Rubinov, A.; Anderson, J.J. (1987): Survival of patients with primary amyloidosis: Colchicine-treated cases from 1976-1983 compared with cases seen in previous years. Am. J. Med., 82:1182-1190.

7. Drury, R.A.B. and Wallington, E.A. (1980): In Carleton's Histological technique. $4^{\text {th }}$ ed. Oxford Univ. Press, New York, Toronto.

8. Eigsti, O.J. and Dustin, Jr. (1955): Colchicine in agriculture, medicine, biology and chemistry. Iowa. State University Press, Ames, Iowa. 391.

9. El-Shafeey, A.; El-Kasaby, A. and Soliman, G. (2000): Histological and histochemical study of spleen of rats treated with colchicine. Egypt. J. Histol., 23(1-2): 139-148.

10. Hood, R.L. (1994): Colchicine poisoning. J. Emerg. Med., 12:171-7.

11. Joshi, H.C. (1998): Microtubule dynamics in living cells. Curr. Opin. Cell Biol., 10:35-44.

12. Kershenobich, D. (1988): Colchicine in the treatment of cirrhosis of the liver. N. Engl. J. Med., 318: 1709-1713. 


\section{Nabila A. R. Abdel Motaal}

13. Kaplan, M.M.; Alling, D.W.; Zimmerman, H.J. (1986): A prospective trial of colchicine for primary biliary cirrhosis. N. Engl. J. Med., 315:144814454.

14. Klintschar, M.; Beham-Schmidt, C.; Radner, H. Henning, G. and Roll, P. (1999): Colchicine poisoning by accidental ingestion of meadow saffron (Colchicum autumnale): pathological and medicolegal aspects. Forensic Sci. Int., 20; 106(3):191200.

15. MacLeod, J.G. and Phillips, L. (1947): Hypersensitivity to colchicine. Ann. Rheum. Dis., 6:224-229.

16. Markland, O.N. (1971): Ultrastructural changes in skeletal muscle induced by colchicine. Arch. Neurol., 24:72-82.

17. Maxwell, M.J.; Muthu, P. and Pritty, P.E. (2001): Accidental colchicines overdose. A case report and literature review. Emerg. Med. J., 19: 265-266.

18. Milne, S.T. and Meek, P.D. (1998): Fatal colchicine overdose: report of a case and review of the literature. Am. J. Emerg. Med., 16:603-608.
19. Naidus, R.M.; Rodiven, R.; Mielke, C.H. (1977): Colchicine toxicity. A multisystem disease. Arch. Intern. Med., 137:394-396.

20. Stahl, N.; Weinberger, A. and Benjamin, D. (1979): Fatal colchicine poisoning in a boy with familial Mediterranean fever. Am. J. Med. Sci., 278:77-81.

21. Stemmermann, G.N. and Hayashi, T. (1971): Colchicine intoxication. A reappraisal of its pathology based on a study of three fatal cases. Hum. Pathol., 2:321-332.

22. US Drug Information for the Health Care Professional: Colchicine. (1998): In: Drug Information for Health Care Professional. Rockville, Maryland: Micromedex, 933-939.

23. Wagenaar, Z. (2004): Accidental colchicines poisoning in a dog. Can. Vet. J., 45(1): 55-57.

24. Zemer, D.; Revach, M. and Pras, M. (1974): A controlled trial of colchicine in preventing attacks of familial Mediterranean fever. N. Engl. J. Med., 291:932-934. 


\title{
دراسة هستولوجية فى طحال و خصية الجرذان المعاملة بالكولثسين
}

\author{
نبيلة عبد الرحمن عبد المتعال \\ قسم بيولوجيا الإشعاع المركز القومى لبحوث و تكنولوجيا الإشعاع- القاهرة-

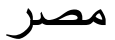

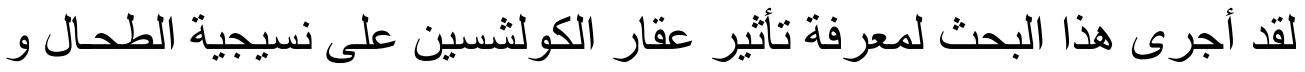

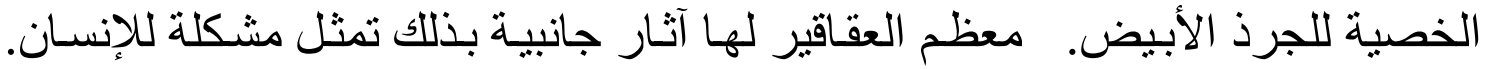

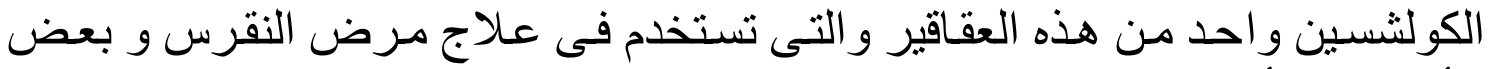

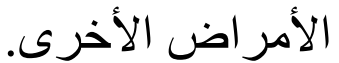

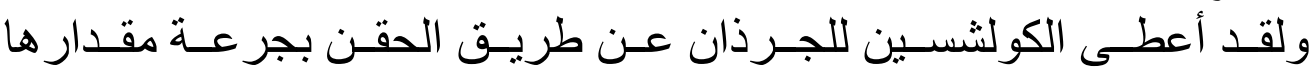

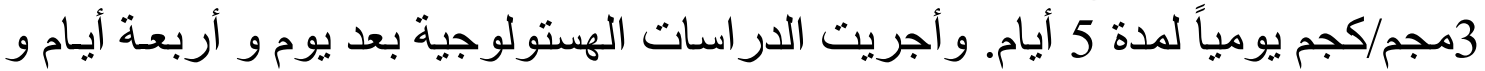
سبعة أيام من تعاطى الكو لثسين.

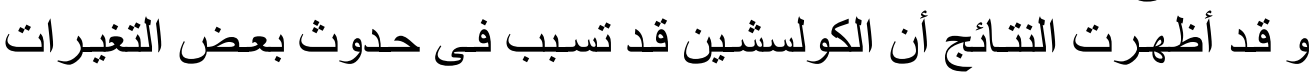

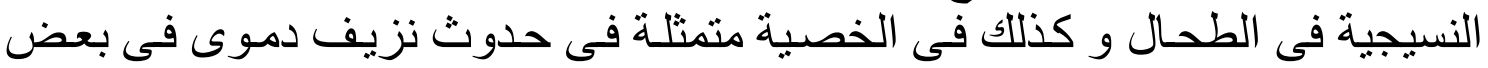

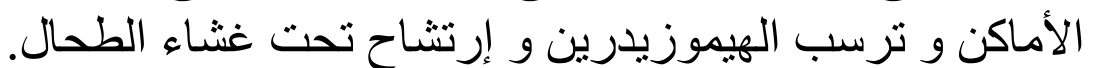

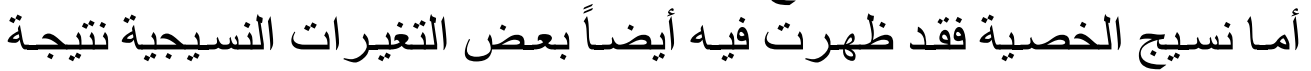
لتعاطى الكو لسشين منمثلة فى : الخئ

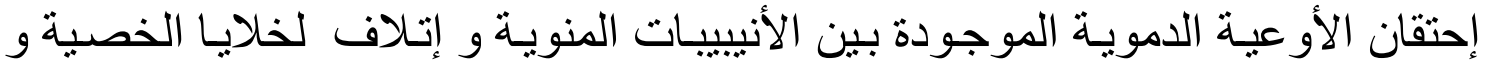
كذلك ظهور الخلايا المنوية العملاقة.

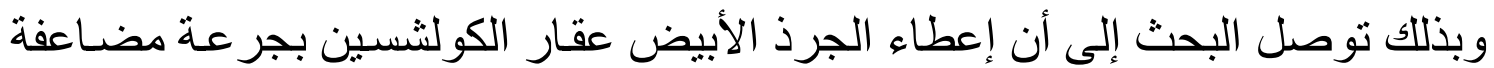
أدى إلى حدوث تغير فى نسيجية الطحال و الخصنية.

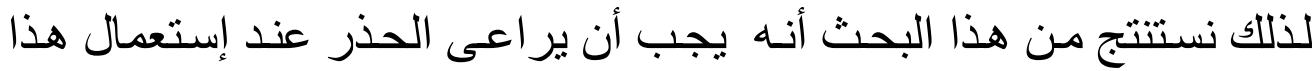

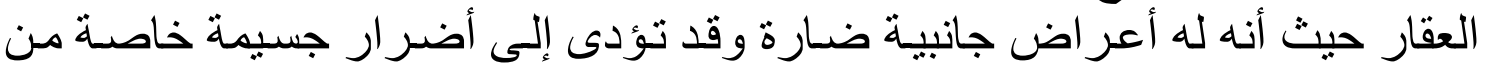
الناحية المناعية و الجنسية. 